\title{
Kurumsal İtibar Algısında Örgütsel İletişimin Rolü: Devlet ve Özel Okullarında Karşılaştırmalı Bir Analiz ${ }^{1}$
}

\author{
DOI: 10.26466/opus.606924
}

\author{
Nuran Çantay* - Okan Yașar** \\ * Öğretmen, Bilfen Eğitim Kurumları, Çamlıca / İstanbul/ Türkiye \\ E-Posta: nurancantay@yahoo.com \\ ORCID: 0000-0002-2020-361X \\ **Dr. Öğr. Üyesi, Beykent Üniversitesi, İ̈BF, Sarıer / İstanbul/ Türkiye \\ E-Posta: okanyasar@beykent.edu.tr \\ ORCID: 0000-0002-5455-4274
}

Öz

Bu araştırma örgütsel iletişimin kurumsal itibar algısı üzerindeki rolünü ortaya koymak amacıyla yapılmıştır. Kurumsal itibar, kurumun paydaşları nazarındaki değer düzeyi olarak tanımlanır ve kurumun faaliyetleri, davranış biçimleri, iletişim yapısı ile doğrudan ilişkilidir. Örgütün gerek kurum çalışanları gerekse diş paydaşlarla oluşturduğu iletişim seviyesi kurumun itibarına yönelik algının şekillendirmesini doğrudan etkilemektedir. Ĕ̆itim kurumları özellikle son yıllarda kamuoyunun ve paydaşlarının daha da yakından ilgilendiği örgütler olarak karşımıza çıkmaktadır. Söz konusu kurumların itibarlarının ne durumda olduğu ve hangi değişkenlerle ilişkili olduğunun anlaşılması önem kazanmıştır. Araştırma ilişkisel tarama modeli çerçevesinde yürütülmüş, örgütsel iletişimin kurumsal itibar üzerindeki etkisini belirlemiş, özel ve devlet okullarının bu değiş̧kenler açısından ayrışıp ayrışmadığını ortaya koymuştur. Araştırmanın verileri, İstanbul ili Küçükçekmece ilçesindeki devlet ve özel okullara ait 288 veli ile 290 okul çalışan olmak üzere toplam 578 kişiden elde edilmiştir. Araştırma bulguları gerek devlet gerekse özel okulların kurumsal itibar algzlarının düşük seviyede olduğunu, örgütsel iletişim ile kurumsal itibar arasında pozitif ilişki olduğunu ortaya koymuş ayrıca, veli ve okul çalışanları arasında kurumların itibarlarına yönelik alt boyutlardan finansal sağlamlık, çalışma ortamı ve kurumsal etik boyutlarında anlaml farklılıklar olduğunu göstermiştir. Araştırma bulguları doğrultusunda eğitim kurumları başta olmak üzere örgütlere önerilerde bulunulmuştur.

Anahtar Kelimeler: Kurumsal itibar, Örgütsel iletişim, Eğitim kurumları, Devlet Okulları, Özel okullar

\footnotetext{
${ }^{1}$ Bu çalışma, Dr.Öğr. Üyesi Okan YAŞAR danışmanlığında Nuran ÇANTAY tarafından hazırlanan yüksek lisans tezinden faydalanılarak derlenmiştir
} 


\title{
The Role of Organizational Communication in Perception of Corporate Reputation: A Comparative Analysis in Public and Private Schools
}

\begin{abstract}
This research was conducted to reveal the role of organizational communication on perception of corporate reputation. Corporate reputation is defined as the level of value of the organization in relation to its stakeholders and is directly related to the activities, behavior and communication structure of the organization. The level of communication that the organization establishes with both corporate employees and external stakeholders directly affects the shaping of the perception about the reputation of the organization. In recent years, educational institutions have emerged as organizations in which public and stakeholders are more closely involved. It is important to understand the status of these institutions and their variables. The research was conducted within the framework of the relational survey model, the relationship between variables was explained and it was revealed whether the private and public schools differ in terms of these variables. The data of the study were obtained from 578 people, 288 parents and 290 school employees belonging to public and private schools in Küçükçekmece district of İstanbul. The findings of the study showed that both public and private schools had low level of corporate reputation perceptions, and there was a positive relationship between organizational communication and corporate reputation, and there were significant differences between parents and school employees in terms of financial soundness, working environment and corporate ethics from the sub-dimensions of corporate reputation. In line with the findings of the research, suggestions were made to organizations, especially educational institutions.
\end{abstract}

Keywords: Corporate reputation, Organizational communication, Educational institutions, Public schools, Private schools. 


\section{Giriş}

Örgütlerin rekabet üstünlüğünü sağlamada sahip olduğu en önemli değeri itibarıdır. Güçlü bir kurumsal itibar, kamuoyunun güvenini artırabilir, paydaş belirsizliğini azaltabilir, rekabet gücünü artırabilir ve kriz veya tehdit zamanlarında örgütü izole edebilir (Fombrun 1996). Tersine, itibar hasarı bir işletme için neredeyse tüm diğer risklerden daha maliyetli olabilir (Jackson 2004) ve yaygın sosyal medya kullanımıyla, hasar potansiyeli her zamankinden büyük olasılıkla daha fazla olur (Aula 2010). Örgütler için itibar kurumsal iletişimin bir fonksiyonudur performansın bileşimi olarak tanımlanır ve örgütlere maddi ve maddi olmayan birçok fayda sağlar. Örgütlerin yaşamları için öne çıkan kritik bir diğer kavram ise paydaş desteğidir ve kurumların paydaşlarıyla kurduğu iletişim, itibar düzeylerinin en önemli belirleyicisidir. Yazında tespit edilen itibar ve iletişim ilişkisinin ölçülmesi örgütler ve yazın için önemli katkılar sağlayacağ 1 açıktır.

Kurumsal iletişim, örgütün bütüncül iletişiminin merkezi yönetimi; o örgütün itibarına ve dolayısıyla rekabet edebilirliğine, verimliliğine ve finansal başarısına önemli bir katkıda bulunur. Bunun yanında kurumsal itibar düzeyi, organizasyon üyeleri ve özellikle yöneticiler ve liderler için artan bir endişe kaynağı olmuştur. Dolayısıyla, kurumsal itibar ve örgütsel iletişim kavramları teorik örtüşmenin yanısıra birçok ortak uygulama alanlarına sahiptir. Bu ortak ilgi alanları, kurumsal itibar kavramıyla ilgili teorik ve ampirik sorular etrafında sıralanır. Alan yazına bakıldığında kurumsal itibarı geliştirmek ve sürdürmek için bir araç olarak iletişime odaklanan çok sayıda yönetim ve işletme olduğu görülmektedir (bkz. Gotsi ve Wilson, 2001; Gray ve Balmer, 1998). Bir diğer alan araştırmaları, çalışan iletişiminin kurum itibarını nasıl etkilediğini veya şekillendirdiğini öne ç1karmaktadır (Smidts ve diğ. 2001).

$\mathrm{Bu}$ araştırmada, bu iki kavramın kesişim alanı eğitim örgütleri perspektifiyle ele alınmış, ayrıca özel ve devlet eğitim kurumlarının karşılaştırmalı değerlendirmesi yapılmıştır. Türkiye'de özel eğitim kurumlarının toplam içindeki payı 2016-2017 eğitim yılında \%15.9 iken, 2017-2018 y1lında \%17.8 olmuştur (MEB, 2019). Bu hızlı yükseliş gerek kamu gerekse veliler nezdinde devlet ve özel eğitim kurumlarının çeşitli boyutlarda sorgulanmasına neden olmaktadır. Araştırmanın örgütler açısından örgütsel 
iletişim ve kurumsal itibar ilişkisini açıklaması, özel ve devlet okullarının bu değişkenler açısından ayrışıp ayrışmadığını ortaya koyması, örgütlere ve araştırmacılara bu alanda öneriler getirmesi açısından alan yazına katkı sağlayacağ1 düşünülmüştür.

\section{Kurumsal İtibar}

İtibar, bir kurumun genel olarak değerlerine ilişkin duyduğu sorumluluğu, güvenilirliği ve gücü üzerinde tutan, bireysel ve kollektif yargıdan oluşmuş bir bütündür (Okay ve Okay, 2014, s.422). Kurumsal itibarı tanımlarken günümüzde en çok kullanılan kuramlar arasında kurumsal kuram ve ona bağlı olarak da meşruiyet kuramı yer almaktadır. Kurumsal kuram, bir kurum ve çevresi arasındaki etkileşimleri inceleyen, kurumsal yönetim felsefesi içindeki temel yaklaşımlardan biridir (Bahar, 2019). Benzer şekilde sosyal kimlik kuramı (Helm, 2011), çalışanların itibar oluşumunda güçlü etkisini ortaya koyarken, paydaş kuramı ve kaynak tabanlı bakış itibarın sonuçlarına ilişkin örgütün rekabet üstünlüğü, finansal performans, müşteri ve çalışan bağlılığı ilişkisini öne sürer (Bahar, 2019).

Kurumsal itibar kavramının çerçevesi Fombrun (1996, s.207) tarafından çizilmeye çalışılmıştır. Bu tanıma göre, kurumsal itibar algısında iki önemli boyutun birleşimine dikkat çekilir. Bunlar örgütün yönetici ve çalışanların oluşturduğu boyut ile örgütün dişından görünümünü ortaya koyan örgütün dışından bakan gözlemcilerin oluşturduğu boyuttur. Kurumsal itibar içsel olarak çalışanlar, dışsal boyutta ise paydaşların algılarının bütüncül bir temsil halidir (Fombrun ve van Riel, 1997: 10). Söz konusu paydaşlar değişen şartlar altında kurumun davranışları ile ilgili çeşitli beklentiler geliştirirler. Bu "itibar beklentileri" kurumlara bazı kazançlar getirdiği gibi bir takım maliyetler de getirmektedir. Kurum sahip olduğu tutum ve davranışlarını, paydaş beklentileri ile paralel devam ettirmemesi halinde, itibar kaybı ve buna bağlı olarak da değer kaybına uğrayacaktır (Greyser 1999, s.180).

Kurumların rakipleri ile kıyaslandığında paydaşlarına yönelik genel kabul edilebilirliğini tanımlayan, geçmiş eylemleriyle, gelecek dönemde yapabileceklerinin algisal anlamda nitelenmesidir (Ural 2006, s.172). Bu sebeple itibarına değer gösteren kurumlar, sadece müşterileri ile iletişim- 
lerine değil bununla birlikte çalışanlar, tedarikçiler, ortaklar ve diğer paydaşlarla olan iletişimlerine de özen göstermektedir. Paydaşlarıyla olan ilişkilerinde prensipli ve tutarlı olan kurumların itibar elde etmeleri ve kazanılan itibarı devam ettirilebilmeleri daha kolay olmaktadır (Besler ve Sarıkaya 2008, s.57).

Araştırmamızda da yazında belirtilen iç paydaşlar kapsamında eğitim kurumunda çalışanlar, dış paydaşlar kapsamında öğrenci velilerinin alg1ları ölçülerek bütüncül bir itibar algısı elde edilmeye çalışılmıştır.

\section{Örgütsel İletişim}

Örgütsel iletişim; insan kaynakları, yönetim, psikoloji, sosyoloji, örgütsel çalışmalar, halkla ilişkiler vb. farklı bakış açılarıyla ele alınan çeşitli araştırma alanlarına sahiptir. Aynı zamanda, işletmelerin, örgütlerin veya grupların kendi iç ortamlarında kendi üyeleriyle veya çalışanlarıyla aynı zamanda kuruluşun bir bütün olarak çevresiyle (müşteriler, müşteriler, satıcılar, tedarikçiler, paydaşlar, medya, genel kamuoyu vb.) iletişim kurma şeklini açıklar. Örgütsel iletişim, bir kuruluşun üyelerinin sağlı̆̆1 için olduğu kadar, kuruluşun diş paydaşları ile olan ilişkisi için de önemlidir (Borca ve Baesu, 2014). Kurumsal iletişim en genel anlamda örgütün iç ve dış paydaşlarıyla oluşturduğu iletişimi temsil eder. Bu alandaki temel kuramlar Goodman, Aberg, Paul Argenti, Van Riel ve Alan Belesan'a ait kuramlardır (Ertekin, Ilgın ve Yengin, 2018) ve örgütsel iletişimin iç ve dış paydaşlarla yürütülmesinin zorunlu olduğunu ve örgütsel itibar fonksiyonunu kapsayan faaliyetler bütünü olduğunu ileri sürer. Ayrıca örgüt kuramlarının gelişimine bakıldığında kuramlar, insan faktörünü merkeze alan bir yapıya bürünmüş, paydaşlarla iletişimin önemine vurgu yapmıştır (Donaldson, 1999).

Kalla (2005), iç iletişim içinde; iş iletişimi (çalışanların iletişim becerilerine ilişkin), yönetim iletişimi (iletişim için yönetim becerileri ve yeteneklerine odaklanmış), kurumsal iletişim (resmi iletişime odaklanmış) ve örgütsel iletişim (felsefi ve teorik yönelimli konular) olmak üzere dört alan tanımlamıştır. Entegre iç iletişim kavramı dört türü de kapsayan bir terimdir ve Berger (2008) kavramı "örgütsel iletişim” olarak ele almıştır. Welch ve Jackson (2007, s.181), paydaş grupların iç iletişimini "iç hat yönetimi 
iletişimi, iç ekip eş iletişimi, iç proje eş iletişimi ve iç şirket iletişimi" olmak üzere yine dört boyutta incelemiştir.

İletişim amaç yönüyle ele alındığında, örgütsel iletişim örgütü oluşturan bireylerin çalışma ve gayretlerini örgüt hedeflerine ulaştıracak şekilde organize etmek, üretim süresini etkin ve etkili biçimde yönetmek amacıyla örgüt üyeleri tarafından simgelerin üretim, iletimi ve yorumu olarak tanımlanmaktadır (Kaya, 2003, s.133). Kuruluşlar büyüdükçe ve daha karmaşık hale geldiklerinde, örgütsel iletişimin örgütsel ihtiyaçlara uyum sağlaması ihtiyacı artar (Ince ve Gül, 2011). Bu bağlamda, belirli bir kuruluştaki iletişim süreçleri, bir ilişki ağında bilgi yaratma ve bilgi alışverişinin yanı sıra, işle ilgili haberleri çalışanlar aracılığıyla çalışanlara iletme ile ilgilidir.

Örgütsel iletişim biçimleri, örgüt ve yönetiminin yapısına göre değişiklikler göstermektedir. Örneğin, örgüt yapısı, dışa dönük, katılımcı, profesyonelce, açık sistem tarzında yapılanmış ve örgüt kültürü de bu yapıyı destekleyici biçimde olduğunda, örgütsel iletişim çok daha rahat kurulabilir. Buna rağmen merkezi, otoriter yapının ve geleneksel kültürlerin yoğun hissedildiği örgütlerde ise, iletişim çok daha güç sağlanır (Tutar, 2003, s.27). Bu araştırmada ele alınan devlet ve özel eğitim kurumları, yapılanma ve kültürel farklılıkları boyutlarında farklılaşacağından iletişim algisında da farklılaşmaya neden olacağı öngörülmüştür. Eğitim örgütlerinde bu durum eğitimin kalitesi ve bağlı olarak da okulun kalitesi ile doğrudan ilintilidir. Yönetim kademesinin örgüt kaynakları ile kurabildiği iletişim, örgütün eylemlerinin yönetimi açısından önemli olup kararlarda da elde edilen sağlıklı bilginin oluşturduğu sağ liklı sonuçlar görülebilecektir. (Gürgen 1997, s.33-34).

Eğitim kurumlarının hem girdisi hem de çıktısı insan olduğu düşünüldüğünde, eğitim dışı örgütlere nazaran iletişimin önemi daha da bir ön plana çıkmaktadır. Yöneticilerin, öğreticilerin, velilerin ve diğer tüm eğitim kurumu çalışanlarının birbirleri ile olan ilişkileri sözel anlatım olsa da olmasa da bir tür iletişim anlamı taşımaktadır (Bolat 1996, s.75).

Örgütün gerek iç gerekse dış paydaşlarının iletişimi örgütün güçlü ve zayıf taraflarının da paylaşılması anlamına gelmektedir. Belmer, Harris ve De Chernatony (2001)'e göre, paydaş gruplarının birçoğu kurumla ilgili bilgileri kurumun çalışanlarından almaktadır. Çalışanların kurumla ilgi 
olumsuz düşünceleri oluştuğunda çalışanlar bunu diş çevreye yansitmakta bu noktadan sonra kurumun dış çevreye yansıtmaya çalıştığı imajı da yetersiz kalmakta ve kurumun itibarı olumsuz yönde etkilenmektedir. Bu yüzden çalışanların desteğini almak güçlü bir kurumsal itibarı devam ettirmek için çok önemlidir (akt. Dörtok 2004, s.74). Dalton ve Croft (2003), kurumların, çalışan ile iletişimin, kurumsal itibar oluşturmadaki rolünü anlamaları gerektiğini vurgulamaktadır. Bunun yanı sıra, kurumsal itibar oluşturabilmek için öncelikle kurum içi iletişimin doğru yönlendirilmesi ve çalışanların dış çevreye kurumla ilgili olumlu mesajlar dağıtmasının sağlanmasının gerekliliğine de işaret etmektedir.

\section{Yöntem}

\section{Araştırmanın Amacı ve Modeli}

Bu araştırmada örgütsel iletişimin kurumsal itibar üzerindeki etkisi belirlenmesi amaçlanmıştır. Örgütlerin uzun süre hayatta kalabilmelerini sağlayacak birçok boyuta etki etmektedir. Örgütsel iletişimi oluşturan boyutlardan kurumların itibarı söz konusu olduğunda hangi boyutların öne çıktığının bilinmesi önemlidir. Kuramsal çerçevede paylaşılan sosyal kimlik kuramı, paydaş kuramı ile örgütsel iletişim kuramları, itibarın örgüte has bir özellik ve ölçülmesi gereken en önemli değeri olduğunu, örgütün paydaşlarıyla kurduğu iletişim sonucunda farklılaşabileceğini, örgütsel iletişimin itibarın oluşum sürecinde önemli girdi olabileceğini ortaya koymuştur. Bu ilişkinin özel ve devlet okulları nezdinde ortaya konması başta eğitim kurumları olmak üzere, itibar kavramına önem veren tüm kurumlar için önemli olacağ düşünülmüştür. Bu kapsamda araştırmada, aşağ1daki soruların cevapları aranmıştır.

1. Çalışanların ve paydaşların örgütsel iletişim ve kurumsal itibar alg1ları ne düzeydedir?

2. Örgütsel itibar ve kurumsal itibar algı değişkenleri özel ve devlet okullarında farklılaşmakta mıdır?

3. Çalışanların örgütsel iletişim seviyelerinin kurumun itibar algıları ile ilişkisi var mıdır? Böyle bir ilişki varsa örgütsel iletişimin kurumsal itibar algısı üzerinde etkisi nedir? 
Araştırmanın yöntemine ilişin oluşturulan model Şekil 1'de gösterilmiştir.

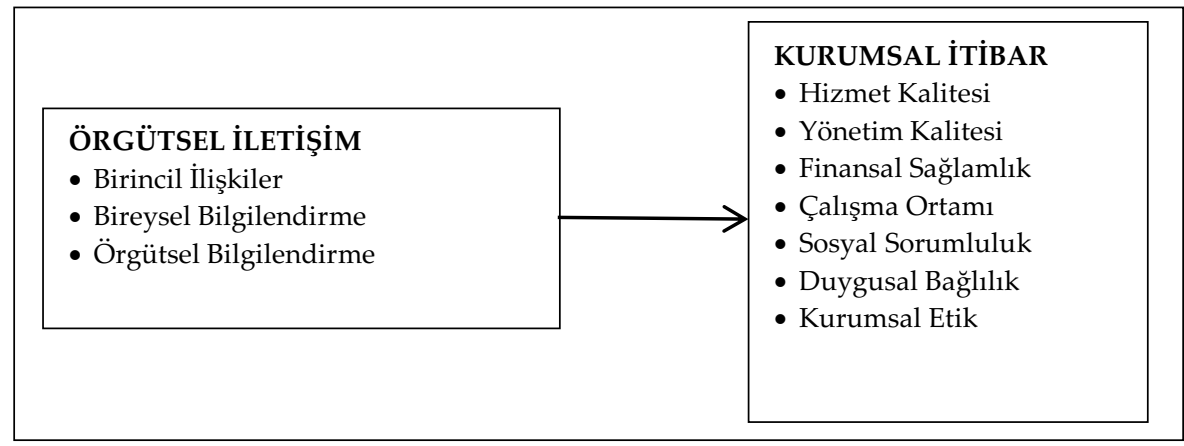

Şekil 1: Araştırma Modeli

\section{Evren ve Örneklem}

Araştırmanın evreni, İstanbul ili Küçükçekmece ilçesi devlet ve özel okulları olarak belirlenmiştir. İlçede 149 devlet okulu, 37 özel okul bulunmaktadır. İlçe Milli Eğitim Müdürlügünden alınan verilere göre evreni oluşturan ilçede devlet ve özel olmak üzere toplam 7953 eğitim çalışanı bulunmaktadır. Bu evreni temsil eden örneklem sayısı \% 95 güven aralığı için 367, \% 99 güven aralığı için 615 olarak tespit edilmiştir (Gürbüz ve Şahin, 2016). Araştırma örneklemini; 183'i özel, 395'i devlet okulu olmak üzere toplam 578 kişiden toplanan veriler oluşturmaktadır. Veriler, paydaş olarak değerlendirilen çalışanlar ve veliler olmak üzere iki gruptan toplanmış, bu nedenle betimsel istatistikleri çalışan ve veli olarak ayrı tablolarda gösterilmiş ve önemli görülen noktalarda fark analizleri yapılmıştır. Örneklemin \%95 güven aralığı için yeterli olduğu, \%99 güven aralığ için yaklaşık değer taşıdığı görülmüştür.

\section{Veri Toplama Araçları}

Araştırmada kullanılan veri toplama araçları okul çalışanları ve veliler için ayrı ayrı kısmi farklılıklar gözetilerek düzenlenmiştir.

Kurumsal itibar ölçeği:Kurumsal itibar algısı, Karaköse (2006) tarafından geliştirilen 40 maddeden oluşan "Kurumsal İtibar Ölçeği" ile ölçülmüştür. 
Karaköse (2006)'nin faktör yapısına sadık kalınarak ölçek alt boyutları belirlenmiş ve bu boyutlarla ilişkin iç tutarlılık katsayıları (Cronbach $\alpha$ ) Tablo 1'de olduğu şekilde tespit edilmiştir.

Tablo 1: Kurumsal İtibar Ölçeği İç Tutarlılık Katsayıları

\begin{tabular}{l|l|l}
\hline Boyutlar & İfadeler & $\alpha$ \\
\hline Hizmet Kalitesi & 1.2 .3 .4 .5 .6$. & 0.74 \\
\hline Yönetim Kalitesi & 7.8 .9 .10 .11$. & 0.73 \\
\hline Finansal Sağlamlık & 12.13 .14$. & 0.80 \\
\hline Çalışma Ortamı & 15.16 .17 .18 .19 .20 .21 .22 .23$. & 0.86 \\
\hline Toplumsal Sorumluluk & 24.25 .26 .27$. & 0.79 \\
\hline Duygusal Çekicilik & 28.29 .30 .31 .32$. & 0.88 \\
\hline Kurumsal Etik & 33.34 .35 .36 .37 .38 .39 .40$. & 0.88 \\
\hline Toplam & $\mathbf{1 - 4 0 .}$ & $\mathbf{0 . 9 5}$ \\
\hline
\end{tabular}

Örgütsel iletişim ölçeği: Örgütsel iletişim algısı, Huseman, Hatfield, Boulton ve Gatewood (1980) tarafından 56 madde olarak geliştirilen ve Özpehlivan (2015) tarafından 24 maddeye düşürülerek Türkçe'ye uyarlanan ölçek ile ölçülmüştür. Bu araştırmada, ölçeğin 24 maddeden oluşan formu kullanılmış ancak yapılan iç tutarlılık analizinde bazı maddelerin güvenilirlik düzeyini düşürdüğü tespit edildiğinden bu maddeler ölçekten çıarılmıştır. Ölçeğin boyutları, boyutlar altında toplanan maddeler ve boyutlara ilişkin iç tutarlılık katsayıları Tablo 2' de verilmiştir.

Tablo 2: Örgütsel İletişim İç Tutarlılık Katsayıları

\begin{tabular}{lll}
\hline Boyutlar & İfadeler & $\boldsymbol{\alpha}$ \\
\hline Bireysel Bilgilendirme & 1.2 .3 & 0.83 \\
\hline Birincil İlişkiler & 5.6 .7 .8 & 0.87 \\
\hline Örgütsel Bilgilendirme & 16.17 .18 .19 .23 .24 & 0.91 \\
\hline Toplam & $\mathbf{1 - 2 4 .}$ & $\mathbf{0 . 9 6}$ \\
\hline
\end{tabular}

\section{Bulgular}

\section{Tanımsal İstatistikler}

Araştırma örneklemine ilişkin demografik özellikler çalışanlar ve veliler olarak Tablo 3 ve Tablo 4' te verilmiştir. 
Tablo 3: Çalışanlara Ait Betimsel İstatistikler

\begin{tabular}{|c|c|c|c|c|c|}
\hline \multirow[b]{2}{*}{ Değişken } & \multirow[b]{2}{*}{ Grup } & \multicolumn{2}{|c|}{ zel Okul } & \multicolumn{2}{|c|}{ Devlet Okulu } \\
\hline & & $\mathrm{n}$ & $\%$ & $\mathrm{n}$ & $\%$ \\
\hline \multirow[t]{3}{*}{ Cinsiyet } & Kadin & 46 & 61,3 & 139 & 64,7 \\
\hline & Erkek & 29 & 38,7 & 76 & 35,3 \\
\hline & Toplam & 75 & 100,0 & 215 & 100,0 \\
\hline \multirow[t]{4}{*}{ Ĕ̆itim } & Lise & 4 & 5,3 & 24 & 11,2 \\
\hline & Lisans & 52 & 69,3 & 154 & 71,6 \\
\hline & Lisansüstü & 19 & 25,3 & 37 & 17,2 \\
\hline & Toplam & 75 & 100,0 & 215 & 100,0 \\
\hline \multirow[t]{6}{*}{ Yaş } & 20-26 Aralığ & 1 & 1,3 & 14 & 6,5 \\
\hline & 27-33 Aralığg & 23 & 30,7 & 56 & 26,0 \\
\hline & 34-40 Aralığ1 & 23 & 30,7 & 52 & 24,2 \\
\hline & 41-46 Aralığ1 & 13 & 17,3 & 48 & 22,3 \\
\hline & 47 ve Üzeri & 15 & 20,0 & 45 & 20,9 \\
\hline & Toplam & 75 & 100,0 & 215 & 100,0 \\
\hline \multirow[t]{3}{*}{ Medeni Durum } & Evli & 63 & 84,0 & 159 & 74,0 \\
\hline & Bekar & 12 & 16,0 & 56 & 26,0 \\
\hline & Toplam & 75 & 100,0 & 215 & 100,0 \\
\hline \multirow[t]{6}{*}{ Toplam çalışma Süresi } & $1-7 Y_{11}$ & 21 & 28,0 & 64 & 29,8 \\
\hline & 8-14 Yil & 24 & 32,0 & 47 & 21,9 \\
\hline & $15-21 Y_{11}$ & 18 & 24,0 & 58 & 27,0 \\
\hline & $22-28 Y_{11}$ & 4 & 5,3 & 25 & 11,6 \\
\hline & 29 Yil ve Üzeri & 8 & 10,7 & 21 & 9,8 \\
\hline & Toplam & 75 & 100,0 & 215 & 100,0 \\
\hline \multirow[t]{5}{*}{ Kurumda Çalıştığı Bölüm } & Öğretmen & 65 & 86,7 & 183 & 85,1 \\
\hline & Müdür Yardımcısı & 3 & 4,0 & 13 & 6,0 \\
\hline & İdari Personel & 5 & 6,7 & 4 & 1,9 \\
\hline & Diğer & 2 & 2,7 & 15 & 7,0 \\
\hline & Toplam & 75 & 100,0 & 215 & 100,0 \\
\hline
\end{tabular}


Tablo 4: Velilere Ait Betimsel İstatistikler

\begin{tabular}{|c|c|c|c|c|c|}
\hline \multirow[b]{2}{*}{ Değişken } & \multicolumn{3}{|c|}{ Özel Okul } & \multicolumn{2}{|c|}{ Devlet Okulu } \\
\hline & Grup & $\mathrm{n}$ & $\%$ & $\mathrm{n}$ & $\%$ \\
\hline \multirow[t]{3}{*}{ Cinsiyet } & Kadın & 67 & 62,0 & 116 & 64,4 \\
\hline & Erkek & 41 & 38,0 & 64 & 35,6 \\
\hline & Toplam & 108 & 100,0 & 180 & 100,0 \\
\hline \multirow[t]{5}{*}{ Eğitim } & İlköğretim & 5 & 4,6 & 31 & 17,2 \\
\hline & Lise & 21 & 19,4 & 96 & 53,3 \\
\hline & Lisans & 28 & 25,9 & 45 & 25,0 \\
\hline & Lisansüstü & 54 & 50,0 & 8 & 4,4 \\
\hline & Toplam & 108 & 100,0 & 180 & 100,0 \\
\hline \multirow[t]{6}{*}{ Yaş } & 20-26 Aralığg & 1 & 9 & 1 & 6 \\
\hline & 27-33 Aralığg & 14 & 13,0 & 25 & 13,9 \\
\hline & 34-40 Aralığ & 43 & 39,8 & 85 & 47,2 \\
\hline & 41-46 Aralığg & 17 & 15,7 & 31 & 17,2 \\
\hline & 47 ve Üzeri & 33 & 30,6 & 38 & 21,1 \\
\hline & Toplam & 108 & 100,0 & 180 & 100,0 \\
\hline \multirow{3}{*}{$\begin{array}{l}\text { Medeni } \\
\text { Durum }\end{array}$} & Evli & 68 & 63,0 & 160 & 88,9 \\
\hline & Bekar & 40 & 37,0 & 20 & 11,1 \\
\hline & Toplam & 108 & 100,0 & 180 & 100,0 \\
\hline \multirow{5}{*}{$\begin{array}{l}\text { Aylık Gelir } \\
\text { Düzeyi }\end{array}$} & 0-5.000 TL Aralığ1 & 21 & 19,4 & 145 & 80,6 \\
\hline & 5.001-10.000 TL Aralığg & 24 & 22,2 & 25 & 13,9 \\
\hline & 10.001-20.000 TL Aralığ1 & 45 & 41,7 & 8 & 4,4 \\
\hline & 20.001 TL ve Üzeri & 18 & 16,7 & 2 & 1,1 \\
\hline & Toplam & 108 & 100,0 & 180 & 100,0 \\
\hline
\end{tabular}

\section{Kurumsal İtibar Değişkenine İlişkin Bulgular}

Kurumsal itibarın okul türünün özel ve devlet olarak farklılaşıp farklılaşmadığı çalışanlar ve veliler bağlamında iki boyutlu olarak sorgulanmış, anlamlı farklılık gösteren boyutlar Tablo 5 ve Tablo 6' da sunulmuştur.

Bulgular incelendiğinde okul türünün çalışanlar için finansal sağlamlık, çalışma ortamı ve kurumsal etik açısından istatistiksel açıdan anlamlı bir farklılık sergilediği görülmektedir. Finansal sağlamlık ve çalışma ortamına ilişkin kurumsal itibar algılarının devlet okulu için daha yüksek olduğu kurumsal etik alt boyutuna ilişkin olarak da özel okul ortalamasının daha yüksek olduğu görülmektedir. Bununla birlikte hizmet kalitesi, yönetim kalitesi, toplumsal sorumluluk ve duygusal çekicilik boyutlarında anlamlı bir farklılık görülmemiştir. 
Tablo 5: Çalışanlar İçin Kurumsal İtibar Alt Boyutlarnın Kurum Türüne Göre Farklilık Düzeyleri

\begin{tabular}{|c|c|c|c|c|c|c|c|c|}
\hline \multirow[t]{2}{*}{ Puan } & \multirow[t]{2}{*}{ Gruplar } & \multirow[t]{2}{*}{$N$} & \multirow[t]{2}{*}{$\overline{\mathrm{X}}$} & \multirow[t]{2}{*}{$S S$} & \multirow{2}{*}{$\mathrm{Sh}_{\overline{\mathrm{x}}}$} & \multicolumn{3}{|c|}{ t-Testi } \\
\hline & & & & & & $t$ & $S d$ & $p$ \\
\hline \multirow{3}{*}{$\begin{array}{l}\text { Finansal } \\
\text { Sağlamlık }\end{array}$} & Özel & 77 & 1,8398 & 77537 & , 08836 & $-2,413$ & 293 & ,016 \\
\hline & Okul & & & & & & & \\
\hline & $\begin{array}{l}\text { Devlet } \\
\text { Okulu }\end{array}$ & 218 & 2,0994 & ,82387 & ,05580 & & & \\
\hline \multirow{3}{*}{$\begin{array}{l}\text { Çalışma } \\
\text { Ortamı }\end{array}$} & Özel & 76 & 1,8041 & ,57288 & ,06571 & $-2,769$ & 286 & ,006 \\
\hline & Okul & & & & & & & \\
\hline & $\begin{array}{l}\text { Devlet } \\
\text { Okulu }\end{array}$ & 212 & 2,0388 & 65427 & ,04494 & & & \\
\hline \multirow[t]{2}{*}{$\begin{array}{l}\text { Kurumsal } \\
\text { Etik }\end{array}$} & $\begin{array}{l}\text { Özel } \\
\text { Okul }\end{array}$ & 74 & 1,8953 & 62689 & ,07287 & 3,102 & 283 & ,002 \\
\hline & $\begin{array}{l}\text { Devlet } \\
\text { Okulu }\end{array}$ & 211 & 1,6576 & ,54477 & 03750 & & & \\
\hline
\end{tabular}

Tablo 6: Veliler İçin Kurumsal İtibar Alt Boyutlarının Kurum Türüne Göre Farklılık Düzeyleri

\begin{tabular}{|c|c|c|c|c|c|c|c|c|}
\hline \multirow[t]{2}{*}{ Puan } & \multirow[t]{2}{*}{ Gruplar } & \multirow[t]{2}{*}{$N$} & \multirow[t]{2}{*}{$\overline{\mathrm{X}}$} & \multirow[t]{2}{*}{$S S$} & \multirow{2}{*}{$\mathrm{Sh}_{\overline{\mathrm{x}}}$} & \multicolumn{3}{|c|}{ t-Testi } \\
\hline & & & & & & $t$ & $S d$ & $p$ \\
\hline \multirow{2}{*}{$\begin{array}{l}\text { Finansal } \\
\text { Sağlamlık }\end{array}$} & Özel Okul & 108 & 2,0216 & ,747 & ,07196 & \multirow[t]{2}{*}{$-3,080$} & \multirow[t]{2}{*}{286} & \multirow[t]{2}{*}{,002 } \\
\hline & $\begin{array}{l}\text { Devlet } \\
\text { Okulu }\end{array}$ & 180 & 2,3167 & 809 & ,06036 & & & \\
\hline
\end{tabular}

Veliler için yalnızca finansal sağlamlık boyutunda farklılık görülmüştür. Velilerin devlet okullarına ilişkin finansal sağlamlık algısının özel okullara göre yüksek olduğu tespit edilmiştir. Veliler için okul türüne bağlı olarak hizmet kalitesi, yönetim kalitesi, toplumsal sorumluluk, çalışma ortamı, duygusal bağlllık ve kurumsal etik değişkenlerinde farklılık görülmemiştir.

\section{Örgütsel İletişim ile Kurumsal İtibar İlişkisine Ait Bulgular}

Araştırmanın temel değişkenleri olan örgütsel iletişim ve kurumsal itibar alt boyutları arasındaki ilişki bulguları Tablo 7' de verilmiştir. Örgütsel bilgilendirme iletişim alt boyutunun, kurumsal itibar boyutlariyla en fazla ilişkili olan boyut olduğu saptanmıştır.

Örgütsel iletişimin kurumsal itibar algısı üzerindeki etkisini tespit etmek amacıyla regresyon analizi yapılmıştır. Hair ve ark. (2006)'na göre, 
VIF değerinin 5,3'ten büyük olması, tolerans değerinin .19'dan küçük olması durumlarının oluşması halinde çoklu bağlantı probleminin varlığına karar verilebilecektir. Bu kriterlere bağlı olarak yapılan veri analizi neticesinde VIF ve tolerans değerlerinin uygun seviyelerde olduğu, değişkenlerin çoklu regresyon analizine tabi tutulabileceği görülmüştür.

Tablo 7. Çalışan Katılımcılar İçin Kurumsal İtibar Örgütsel İletişim İlişkisi

Hizmet Kalitesi 1

\begin{tabular}{|c|c|c|c|c|c|c|c|c|c|c|}
\hline & 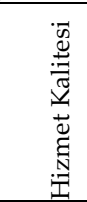 & 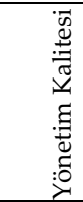 & 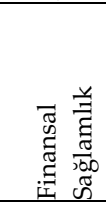 & 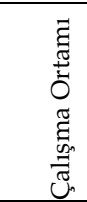 & 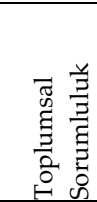 & 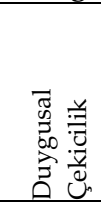 & 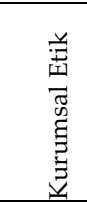 & 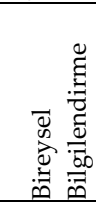 & 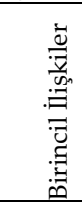 & 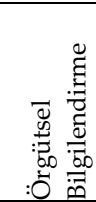 \\
\hline \multicolumn{11}{|c|}{ Hizmet Kalitesi 1} \\
\hline \multicolumn{2}{|c|}{ Yönetim Kalitesi,409** } & 1 & & & & & & & & \\
\hline $\begin{array}{l}\text { Finansal } \\
\text { Sağlamlık }\end{array}$ & $493^{* *}$ &, $567^{* *}$ & 1 & & & & & & & \\
\hline Çalışma Ortamı & $495^{* *}$ & $839^{* *}$ & $750^{* *}$ & 1 & & & & & & \\
\hline $\begin{array}{l}\text { Toplumsal So } \\
\text { rumluluk }\end{array}$ &, $534^{* *}$ &, $749^{* *}$ &, $712^{* *}$ &, $828^{* *}$ & 1 & & & & & \\
\hline $\begin{array}{l}\text { Duygusal } \\
\text { Çekicilik }\end{array}$ &, $382^{* *}$ &, $765^{* *}$ &, $730^{* *}$ &, $885^{* *}$ &, $732^{* *}$ & 1 & & & & \\
\hline Kurumsal Etik & $335^{* *}$ & $679 * *$ &, $591^{* *}$ & $779 * *$ & $601^{* *}$ & $742^{* *}$ & 1 & & & \\
\hline $\begin{array}{l}\text { Bireysel } \\
\text { Bilgilendirme }\end{array}$ &, $415^{* *}$ &, $591^{* *}$ &, $292^{* *}$ & .202 &, $547^{* *}$ & $652^{* *}$ &, $710^{* *}$ & 1 & & \\
\hline Birincil İlişkiler & $349^{* *}$ &, $590^{* *}$ & $344^{* *}$ & .278 &, $501^{* *}$ & $586^{* *}$ & $642^{* *}$ &, $760 * *$ & 1 & \\
\hline $\begin{array}{l}\text { Örgütsel } \\
\text { Bilgilendirme }\end{array}$ &, $431^{* *}$ & $685^{* *}$ &, $338^{* *}$ & $775^{* *}$ &, $660^{* *}$ &, $744^{* *}$ &, $772^{* *}$ & $838^{* *}$ &, $852^{* *}$ & 1 \\
\hline
\end{tabular}

Kurumsal itibarın alt boyutu olan hizmet kalitesi ile örgütsel iletişim alt boyutları arasında yapılan regresyon analizi neticesinde oluşturulan üçlü modelin hizmet kalitesini \%21,9 oranında yordadığı, yönetim kalitesini $\% 48,8$ oranında yordadığı, toplumsal sorumluluk değişkenini $\% 45,2$ oranında, duygusal çekicilik değişkenini \%57,2 oranında yordadığı, kurumsal etik değişkenini \%63,6 oranında yordadığı görülmüştür (Tablo 8). 
Tablo 8: Örgütsel İletişimin Kurumsal İtibar Boyutlarnı Yordama Düzeyi

\begin{tabular}{|c|c|c|c|c|c|c|c|c|}
\hline \multicolumn{2}{|c|}{ Hizmet Kalitesi } & & \multirow{2}{*}{$\begin{array}{l}\mathbf{R 2} \\
188\end{array}$} & \multirow{2}{*}{$\begin{array}{l}\mathbf{F} \\
61,928^{*}\end{array}$} & \multirow{2}{*}{$\begin{array}{l}\beta \\
433\end{array}$} & \multirow{2}{*}{$\begin{array}{l}\text { Kismi r } \\
433\end{array}$} & \multirow{2}{*}{$\begin{array}{l}\text { tole- } \\
\text { rans } \\
1\end{array}$} & \multirow{2}{*}{$\begin{array}{l}\text { VIF } \\
1\end{array}$} \\
\hline Model 1 & $\begin{array}{l}\text { Bireysel } \\
\text { Bilg. }\end{array}$ & & & & & & & \\
\hline \multirow[t]{2}{*}{ Model 2} & \multirow{2}{*}{$\begin{array}{l}\text { Bireysel Bilg. } \\
\text { Birincil İlişkiler }\end{array}$} & \multirow[t]{2}{*}{,451 } & \multirow[t]{2}{*}{ 203 } & \multirow[t]{2}{*}{$34,004^{*}$} & ,334 & 281 & \multirow[t]{2}{*}{0,610} & \multirow[t]{2}{*}{1.640} \\
\hline & & & & & , 158 & 137 & & \\
\hline \multirow[t]{3}{*}{ Model 3} & \multirow{3}{*}{$\begin{array}{l}\text { Bireysel Bilg. } \\
\text { Birincil İlişkiler } \\
\text { Örgütsel Bilg. }\end{array}$} & \multirow[t]{3}{*}{,468 } & \multirow[t]{3}{*}{219} & \multirow[t]{3}{*}{$24,904^{*}$} & ,218 & ,155 & \multirow[t]{3}{*}{0,266} & \multirow[t]{3}{*}{1.640} \\
\hline & & & & & ,036 & ,026 & & \\
\hline & & & & & ,250 & ,143 & & \\
\hline \multicolumn{9}{|c|}{ Yönetim Kalitesi } \\
\hline Model 1 & Bireysel Bilg. & ,581 & ,338 & $136,550^{*}$ &, 581 & ,581 & 1 & 1 \\
\hline \multirow[t]{2}{*}{ Model 2} & \multirow{2}{*}{$\begin{array}{l}\text { Bireysel Bilg. } \\
\text { Birincil İlişkiler }\end{array}$} & \multirow[t]{2}{*}{ 652 } & \multirow[t]{2}{*}{425} & $98,755^{*}$ & ,345 & ,336 & 612 & 1,633 \\
\hline & & & & & ,378 & ,364 & & \\
\hline Model 3 & Bireysel Bilg. & 699 & 488 & $84,599^{*}$ & ,117 & ,104 & ,407 & 2,457 \\
\hline & Birincil İlişkiler & & & & , 140 & ,122 & & \\
\hline & Örgütsel Bilg. & & & & 490 & ,331 & & \\
\hline Toplums & Sorumluluk & & & & & & & \\
\hline Model 1 & Bireysel Bilg. &, 550 & ,302 & $113,567^{*}$ &, 550 & ,550 & 1 & 1 \\
\hline Model 2 & Bireysel Bilg. & ,591 & 350 & $70,208^{*}$ & ,375 & ,340 & 607 & 1,648 \\
\hline & Birincil İlişkiler & & & & ,280 & 261 & & \\
\hline Model 3 & Bireysel Bilg. & 672 & 452 & $71,426^{*}$ & ,086 & ,074 & 406 & 2,463 \\
\hline & Birincil İlişkiler & & & &,- 019 &,- 016 & & \\
\hline & Örgütsel Bilg. & & & & ,618 & ,396 & & \\
\hline Duygusa & ekicilik & & & & & & & \\
\hline Model 1 & Bireysel Bilg. & 660 & 435 & $203,629^{*}$ & 660 & 660 & 1 & 1 \\
\hline Model 2 & Bireysel Bilg. & 698 & 487 & $125,062^{*}$ & ,478 & 463 & 611 & 1,635 \\
\hline & Birincil İlişkiler & & & & ,292 & ,304 & & \\
\hline Model 3 & Bireysel Bilg. & 756 &, 572 & $116,702^{*}$ & ,212 & 202 & 399 & 2,508 \\
\hline & Birincil İlişkiler & & & & , 020 & 019 & & \\
\hline & Örgütsel Bilg. & & & &, 565 & 406 & & \\
\hline Kurumsa & tik & & & & & & & \\
\hline Model 1 & Bireysel Bilg. & ,709 &, 503 & $265,989^{*}$ & ,709 & ,709 & 1 & 1 \\
\hline Model 2 & Bireysel Bilg. & ,755 &, 570 & $173,724^{*}$ &, 500 &, 511 & 606 & 1,650 \\
\hline & & & & & ,333 & 368 & & \\
\hline & Birincil İlişkiler & & & & & & & \\
\hline Model 3 & Bireysel Bilg. & 797 & 636 & $151,864^{*}$ & ,265 & 269 & ,399 & 2,509 \\
\hline & Birincil İlişkiler & & & & ,096 & 100 & & \\
\hline & Örgütsel Bilg. & & & & ,497 & 391 & & \\
\hline
\end{tabular}

${ }^{*} p<, 01$ 


\section{Tartışma, Sonuç ve Öneriler}

Bu çalışmada, kurumsal itibar ile örgütsel iletişimin ilişkisi ve iletişimin kurumsal itibara etkisi incelenmiştir. Araştırma verileri devlet ve özel eğitim kurumlarından ayrı ayrı toplandığından her iki değişkene ait algıların özel ve devlet okulları bağlamında karşılaştırma yapılmasına imkân sağlamıştır.

Yazında, kurumsal itibarın kurumlar açısından devamlılıklarını sağlama ve hedef kitleleri ile olan ilişkilerini devam ettirme kapsamında hayati önem taşıyan bir unsur olduğu belirtilmektedir. Kurum, itibarını oluşturacak olan faaliyetlerini, özelliklerini, yaklaşımlarını, misyon ve vizyonu gibi hedef kitlenin ilgisini çekecek hususları hedef kitleye aktarabilmektedir. Özellikle de eğitim gibi tamamen iletişim yoluyla sağlanan bir hizmet sektöründe kurum içi iletişimin öneminin tartışılmazlığı da yazında genel kabul görmektedir. Örgütsel iletişim ile kurumsal itibar ilişkisi sorunsalı kapsamında oluşturulan araştırma sorularına yönelik bulgular aşağıda tartışılmıştır.

Demografik değişkenlerden cinsiyet yaş, eğitim durumu, medeni durum değişkenlerinin kurumsal itibar açısından farklılık olmadığı görülmüştür. Literatürde yer alan çalışmaların birçoğunda belirtilen bulgular da bu yönde olup araştırmada elde edilen analiz sonuçlarını destekler niteliktedir (Acet, 2006; Gültekin, 2003; Şatır ve Sümer, 2008). Bu bulgulardan hareketle kurumsal itibarın genel kanaat içeren bir durum olduğunu ve kişisel özelliklerin bu durumun algılanmasında çok düşük düzeyde etkiye sahip olduğunu söylemek mümkündür.

Eğitim kurumlarının iletişim ve itibar algıları özel ve devlet okulları bağlamında aşağıda tartışılmıştır. Ancak bulgularda değişkenlere ilişkin anlamlı farklılıklar olsa da genel anlamda eğitim kurumlarının hem kurumsal itibar hem de örgütsel iletişim seviyelerinin düşük olduğu söylenebilir. Ulusal yazında benzer çalışmalarda; eğitim kurumlarında iletişim algisının düşük olduğu (Kaya, 1999), özellikle iç iletişim yeterli düzeyde olmadığı, öğretmenler okul müdürleri arasında algısal farklılıklar olduğu bulguları araştırma bulgularıyla paralellik göstermektedir.

Finansal sağlamlık ile çalışma ortamı alt boyutları devlet okulu çalışanlarında kurumsal etik boyutu ise özel okul çalışanları algısında daha yüksek olduğu görülmüştür. Devlet okulları çalışanları arasında okulun 
ekonomik yapısına güven, çalışanlar arasında dayanışma seviyesi ile okula olan güven duygusunun görece daha yüksek olduğu görülmüştür. Buna karşın, özel okul çalışanlarında kurumsal etik boyunu oluşturan; ödül ve ceza kavramlarının adilce uygulanması, okul imkânlarından faydalanma, öğrencilerin daha objektif değerlendirilmesi görece daha yüksektir. Hizmet ve yönetim kalitesi ile toplumsal sorumluluk ve duygusal bağlanma anlamında fark görülmemesi de anlamlı bir diğer bulgu olarak karşımıza çıkmaktadır.

Kurumsal itibar algısına veli penceresinden bakıldığında sadece finansal sağlamlık boyutunda devlet okulu velilerinin daha yüksek algıları olduğu görülmektedir. Devlet ve özel okul ayrımındaki yukarıda belirtilen anlamlı farklılık her ne kadar devlet okullarının itibar algılarının özel okullara göre daha yüksek olduğunu gösterse de, bunun hem çalışan hem veli beklentisiyle de ilgili olabileceği düşünülebilir. Ayrıca anlamlı farkl1lığa rağmen her iki paydaş grubunun, itibar puanlarının düşük olması, hem devlet hem özel okulların veli ve çalışanların beklentilerini karşılamadığ ş̧eklinde yorumlanabilir.

Örgütsel iletişim ile kurumsal itibar değişkenlerinin ilişkili olduğu ve iletişim değişkeninin alt boyutlarının kurumun itibar algısı düzeyini etkilediği korelasyon ve regresyon analizlerinde görülmüştür. Gümüş ve Öksüz (2009), çalışmasındaki iletişimin örgütsel başarı ve itibarı artırıcı etkisi bu bulguyla örtüşmektedir. Bu kapsamda elde edilen veriler değerlendirildiğinde; hizmet kalitesi ile örgütsel iletişim ilişkisinde örgütsel iletişimin hizmet kalitesini toplamda \%21,9 oranında yordadığı ve bu oran içerisinde en büyük payın bireysel bilgilendirmenin (\%18,8) olduğu görülmektedir.

Yönetim kalitesine ilişkin örgütsel iletişimin etkisi değerlendirildiğinde ise yönetim kalitesi ile örgütsel iletişim arasında \%48,8 düzeyinde bir ilişkinin varlığı dikkat çekmektedir. Bu oran içerisinde yönetimin çalışanları bireysel olarak bilgilendirmesi suretiyle kurulan iletişimin payı \%33,8 düzeyindedir. Bu oran, diğer değişkenlerle kıyaslandığında; bireysel bilgilendirme ile yönetim kalitesi arasındaki ilişkinin diğer değişkenlerden daha yüksek olduğu ve yönetimin çalışanlarla kurduğu iletişimin kurumsal itibarı en üst düzeyde etkileyen değişkenlerden olduğu söylenebilir. 
Çalışma koşullarına ilişkin kurumsal itibar algısında etkisi olan örgütsel iletişim değişkeninin yalnızca örgütsel bilgilendirme olduğu görülmüş ve çalışanların kararlara, faaliyetlere, etkinliklere dahil edilmesi anlamında olan örgütsel bilgilendirmenin çalışma koşullarına ilişkin etkisi \%44,9 düzeyinde görülmüştür. Bu durum, çalışanların yönetimle iş bağlamında oluşan iletişimin kalitesinin önemini de ortaya koymaktadır.

Kurumsal itibarı oluşturan toplumsal sorumluluk boyutunda örgütsel iletişimin etkisinin \%45,2 olduğu görülmektedir. Bu oran, örgütsel iletişimde toplumsal sorumluluk konularının önemini göstermektedir. Ayrıca bu oran içerisinde birincil ilişkiler \%30,2 gibi bir öneme sahiptir. Birincil ilişkilerin bu denli belirleyici olmasının çalışanların kurum tarafından gördükleri önemle ilişkilendirilmesi yerinde olacaktır. Nitekim kurumun çalışanlara verdiği önem onlarla olan iletişimiyle ortaya çıkacak ve bu durum da sağlıklı ve etkili bir iletişime bağlı olarak çalışan algısında pozitiflik olarak kendini gösterecektir. Bu savı destekler nitelikteki araştırma bulgusu ise duygusal çekicilik ile örgütsel iletişim arasındaki ilişki olmaktadır. Duygusal çekiciliğin örgütsel iletişimden etkilenme düzeyi \%57,2 oranında olduğu görülmüştür. Kurumsal itibar boyutları içerisinde örgütsel iletişim ile yüksek oranda ilişki sergileyen değişken olarak kendini gösteren duygusal çekicilik, bireylerin kuruma karşı besledikleri duyguları ifade etmekte ve bu duyguların da kurumsal itibarı şekillendirmede önemli olduğunu göstermektedir. Nitekim bu oran içerisinde $\% 43,5^{\prime}$ lik payın birincil ilişkiler olması bu yargıyı destekler niteliktedir.

Son olarak kurumsal etik ve örgütsel iletişim ilişkisi değerlendirildiğinde, örgütsel iletişimin kurumsal etik değişkenini \%63,6 oranında yordadığ1 görülmektedir. Kurumsal etik, diğer değişkenlerle benzer şekilde kurumun etik algısını ve dolayısıyla iç paydaşlar olan çalışanlarla oluşturduğu iletişimin etik boyutunu da ifade etmektedir. Bu sebeple, örgütsel iletişim kurumsal etik algısının oluşumunda etkin bir rol üstlenmektedir. Uluslararası çalışmalarda da; yönetici ve öğretmenler arasındaki iletişimin, verimlilik kültürünün oluşumunu beslediği, dış paydaşların da bu gelişimden olumlu yönde etkilendikleri (Jhonson, Snyder, Anderson, Jhonson, 1996), yine örgütsel iletişimin çalışanların davranışlarını ve tutumlarını etkilediği (Argenti ve Druckenmiller, 2004) kurumsal itibarı yükseltttiği (Balmer, Harris ve de Chernatony, 2001), bütünsellik içeren 
iletişim yapısının güçlü kurumsal itibara oluşturduğu (Malmelin, 2007) görülmektedir.

Sonuç olarak; hem çalışanların hem velilerin kurumsal itibar ve iletişim algılarının düşük olduğu, bununla birlikte çalışanların örgütsel iletişim seviyelerinin kurumun itibar algısı ile ilişkili olduğu, iletişimin en fazla etkilediği kavramların kurumsal etik, duygusal çekicilik ve yönetim kalitesi olduğu görülmüştür. Devlet ve özel okul karşılaştırması kapsamında; devlet okullarının finansal sağlamlık ve çalışma koşuları boyutlarıyla özel okullara görece yüksek algıya sahip oldukları, özel okulların ise kurumsal etik boyutunda görece yüksek algıya sahip olduğu söylenebilir.

Gerek devlet gerekse özel okulları tarafından çalışanlarıyla kurdukları örgütsel iletişim seviyelerini, aynı şekilde veli ve çalışanların eğitim kurumlarına ilişkin itibar algılarını artırıı tedbirler almaları gerektiği açıtır. Hutton, Goodman, Alexander ve Genest' in (2001) Fortune 500 şirketleri üzerinden yaptıkları araştırmada kurumsal iletişimin en yüksek etkisinin itibarı yönetmek, paydaşlara bilgi sağlanması faaliyetleri üzerinde olduğunu bildirmektedirler. Kurumsal itibarlarının en önemli iki paydaşları olan okul çalışanları ile öğrenci velileri nezdinde yükseltilmesi okullara ve eğitime duyulan güven ve bağlılık kavramlarını da artıracağı söylenebilir. Bu amaçla, devlet okullarının ödül ve ceza uygulamalarında, öğrencilerin değerlendirilmesi konularında etik davranışlara daha önem vermesi gerektiği, özel okulların ise, özellikle çalışanlar arasında güven duygusunu artıracak ve dayanışmayı sağlayacak uygulamalarda bulunmasının önemli olduğu söylenebilir.

Bu sonuçlardan hareketle, eğitim kurumlarının sağlıklı kurum içi iletişimin kurum itibarını doğrudan etkilediğini dikkate almak suretiyle hareket etmeleri uygun davranış tarzı olacaktır. Diğer taraftan, yönetim mekanizmasının tekil bir yapı olmayıp iç ve dış paydaşlar ile bütüncül olmak zorunda olması, bu yapının sağlıklı bir iletişim yoluyla koordinesinin aynı zamanda yönetimin başarısı olarak yansıyacağı göz ardı edilmemelidir. Öte yandan, iç paydaşların kurumu ifade etme biçimlerine de yansıyacak olan bu durum diş paydaşlar nezdinde de kurumun itibar düzeyini yükseltecek ve var oluş amacına hizmet etmesine katkı sağlayacaktır.

Benzer araştırmaların farklı örgüt tiplerinde uygulanarak alana bilgi birikimi sağlayacağı değerlendirilmiştir. Ayrıca, değişen teknoloji ile iletişim çeşitlerinin değiştiği gerek örgütsel gerekse dış paydaşlarla iletişimde 
Kurumsal İtibar Algısında Örgütsel İletişimin Rolü: Devlet ve Özel Okullarında Karşılaştırmalı Bir Analiz

sosyal medya olmak üzere yeni iletişim araçlarının kullanıldığı görülmektedir. Bunun sonucu olarak kurumsal itibar algılarının yönetilmesi ve ölçülmesi konularında da çeşitlenme kaçınılmazdır. Bu anlamda kullanılan değişkenlerin sosyal medya verileriyle araştırılması alana derinlik ve zenginlik katacaktır. 


\title{
EXTENDED ABSTRACT
}

\section{The Role of Organizational Communication in Perception of Corporate Reputation: A Comparative Analysis in Public and Private Schools}

\author{
Nuran Çantay - Okan Yaşar \\ Bilfen Education Institution, Beykent University
}

The most important value that organizations have in ensuring competitive advantage is their reputation. A strong corporate reputation can increase public confidence, reduce uncertainty for stakeholder, increase competitiveness and protect organization in times of crisis or threat (Fombrun 1996). Conversely, reputation damage can cost more for a business than almost any other risk (Jackson 2004), and with widespread use of social media, the potential for damage is more likely than ever (Aula 2010). Reputation for organizations is defined as a combination of performance, a function of corporate communication, and provides many tangible and intangible benefits to organizations. Another critical concept that stands out for the lives of organizations is stakeholder support and the communication established by institutions with their stakeholders is the most important determinant of their reputation levels. Measuring the relationship between reputation and communication identified in the literature will make significant contributions to organizations and also to literature.

Corporate communication, management of the organization's holistic communication; makes an important contribution to the organization's reputation and therefore to its competitiveness, efficiency and financial success. In addition, the level of corporate reputation has been an increasing concern for members of the organization and especially for managers and leaders. Therefore, the concepts of corporate reputation and organizational communication have many common application areas as well as theoretical overlap. These common interests are centered around theoretical and empirical questions about the concept of corporate reputation. As seen in the literature, there are many organizations use communication to develop and maintain corporate reputation (see Gotsi and Wilson, 2001; 
Gray and Balmer, 1998). Other field studies also highlight how employee communication affects or shapes corporate reputation (Smidts et al., 2001).

\section{Model and Purpose Research}

In this study, it is aimed to determine the effect of organizational communication on corporate reputation. In the research, the answers to the following questions were sought.

1. What are the level of perceptions of employees and stakeholders on organizational communication and corporate reputation?

2. Do the organizational reputation and institutional reputation perception variables differ in private and public schools?

3. Is the level of perception of organizational communication related to the perception of reputation of the organization of the employees? If so, what is the impact of organizational communication on corporate reputation perception?

The population of the research was determined as public and private schools of Küçükçekmece district of İstanbul. There are 149 public and 37 private schools in the district. According to the data obtained from the Directorate of National Education, there are 7953 public and private employees in the district that make up the research population. The number of samples representing this population was determined as 367 for $95 \%$ confidence interval and 615 for $99 \%$ confidence interval (Gürbüz and Şahin, 2016). Research sample; The data is collected from 578 people, 183 of which are private and 395 of which are public schools.

\section{Research Scales}

The data collection tools used in the study were arranged separately for school employees and parents.

Corporate reputation scale: Corporate reputation perception was measured by the Corporate Reputation Scale which consists of 40 items developed by Karaköse (2006).

Organizational communication scale: Organizational communication perception was measured with a scale developed by Huseman, Hatfield, 
Boulton and Gatewood (1980) and adapted to Turkish by reducing to 24 items by Özpehlivan (2015).

\section{Findings}

The question of whether corporate reputation differs in private and governmental dimensions has been questioned in the context of employees and parents.

When the findings are examined, it is seen that the school type shows a statistically significant difference in terms of financial soundness, working environment and corporate ethics for the employees. It is seen that the perception of financial credibility and the corporate reputation regarding the working environment is higher for the public school and the private school average is higher in terms of ethical sub-dimension. However, there was no significant difference in service quality, management quality, social responsibility and emotional attractiveness. There was only a difference in financial robustness for parents. Parents' perception of financial soundness of public schools was found to be higher than that of private schools. There was no difference in terms of service quality, management quality, social responsibility, working environment, emotional commitment and institutional ethics. The organizational information communication sub-dimension was found to be the most related to the corporate reputation dimensions.

As a result of the regression analysis made between service quality, which is the sub-dimension of corporate reputation, and organizational communication sub-dimensions, the triple model predicted service quality by $21.9 \%$, predicted quality of management by $48.8 \%$, and social responsibility variable by $45.2 \%$, predicted emotional attractiveness by $57.2 \%$ and predicted institutional ethics by $63.6 \%$.

\section{Conclusion, Discussion and Suggestions}

In this study, the relationship between organizational reputation and organizational communication and the effect of communication on corporate reputation are examined. Since the research data were collected separately from public and private educational institutions, perceptions of 
both variables could be compared in the context of private and public schools.

Communication and reputation perceptions of educational institutions are discussed below in the context of private and public schools. However, although there are significant differences in the findings regarding the variables, it can be said that both institutional reputation and organizational communication levels of educational institutions are low in general. In similar studies in Turkey; The findings of the study indicate that the perception of communication in educational institutions is low (Kaya, 1999), especially internal communication is insufficient, and there are perceptual differences between teachers and school principals.

As a result; It was observed that both employees 'and parents' perceptions of corporate reputation and communication were low, however, organizational communication levels of employees were related to the perception of reputation of the organization, and the concepts that most affected by communication were corporate ethics, emotional attractiveness and management quality. In the context of public and private school comparisons; it can be said that public schools have a relatively high perception of private schools in terms of financial soundness and working conditions, while private schools have a relatively high perception of institutional ethics.

It has been evaluated that similar researches will be applied in different types of organizations to provide knowledge in the field. In addition, it is seen that the changing technology and communication types have changed and new communication tools, social media, have been used in communication with both organizational and external stakeholders. As a result, diversification is inevitable in the management and measurement of corporate reputation perceptions. Researching the variables used in this sense with social media data will enrich the literature.

\section{Kaynakça / References}

Acet, Ö. (2006). Illköğretim okullarında örgüt iklimi ile karara katılma süreci arasındaki ilişki. Doktora Tezi, DEÜ Eğitim Bilimleri Enstitüsü, İzmir.

Argenti, P. A., ve Druckenmiller, B. (2004). Reputation and the corporate brand. Corporate reputation review, 6(4), 368-374. 
Aula, P. (2010). Social media, reputation risk and ambient publicity management. Strategy and Leadership, 38(6), 43-49.

Bahar, B. (2019). Kurumsal itibar ve kuramsal temelleri. Journal of Yasar University, 14(55), 226-236.

Balmer, J. M., Harris, F., ve de Chernatony, L. (2001). Corporate branding and corporate brand performance. European Journal of marketing, 35(3/4),441-456.

Berger, C. R. (2008). Planning theory of communication. Sage Publications, Inc.

Berger, B. K. (2008). Employee/organization communication. Miami, FL: Institute for Public Relations. Available at http://www.instituteforpr.org/topics/employee-organizational-communications/

Besler, S. ve Sarıkaya, M. (2008). Kurumsal itibarı yaratmada kurumsal paydaş yönetimi ve medya ile ilişkilerin önemi, Muhan Soysal İşletmecilik Konferans1: İşletmecilikte Yeni Gelişmeler ve Fırsatlar, 143-153.

Bolat, S. (1996). Eğitim örgütlerinde iletişim: H. Ü. eğitim fakültesi uygulaması. Hacettepe Üniversitesi Ĕ̆itim Fakültesi Dergisi, 12, 75 - 80.

Borca, C., ve Baesu, V. (2014). A possible managerial approach for internal organizational communication characterization. Procedia-Social and Behavioral Sciences, 124, 496-503.

Dalton, J., ve Croft, S. (2003). Managing corporate reputation. London: Thorogood.

Donaldson, T. (1999). Making stakeholder theory whole. Academy of Management Review, 24(2), 237-241.

Dörtok, A. (2004). Kurumsal itibarınızdan kaç sıfır atabilirsiniz. İstanbul:Rota Yayınları.

Ertekin, İ., İlgin, H. Ö., ve Yengin, D. A. (2017). Örgütsel iletişim kuramlar1. The Turkish Online Journal of Design Art and Communication, 8(2), 297-311.

Fombrun, C. J. (1996). Reputation: Realizing value from the corporate image. Boston:Harvard Business School Press. 1st Press,

Fombrun, C., ve Van Riel, C. (1997). The reputational landscape. Corporate reputation review, 1(1-2), 1-16.

Gray, E.R. and Balmer, J.M.T. (1998) Managing corporate image and corporate reputation. Range Planning, 31, 695-702.

Gotsi, M. ve Wilson, A.M. (2001) Corporate reputation: Seeking a defi nition . Corporate Communications: An International Journal, 6, 24-30.

Gürgen, H. (1997). Örgütlerde iletişim kalitesi. İstanbul:Der Yayınları. 
Greyser, S. A. (1999). Advancing and enhancing corporate reputation. Corporate Communications: An International Journal, 4(4), 177-181.

Hair, J. F., Anderson, R. E., Tatham, R. L., ve Black, W. C. (2006). Multivariate data analysis (6th Ed.). Upper Saddle River, NJ: Prectice-Hall, Inc.

Helm, S. (2011). Employees' awareness of their impact on corporate reputation. Journal of Business Research, 64(7), 657-663.

Hutton, J. G., Goodman, M. B., Alexander, J. B., ve Genest, C. M. (2001). Reputation management: the new face of corporate public relations?. Public Relations Review, 27(3), 247-261.

Ince, M. ve Gül, H. (2011). The role of the organizational communication on employees' perception of justice: A sample of public institution from Turkey. European Journal of Social Sciences. 21(1), 106-124..

Jackson, K. T. (2004). Building reputational capital: Strategies for integrity and fair play that improve the bottom line. Oxford University Press.

Johnson, W. L., Snyder, K. J., Anderson, R. H., ve Johnson, A. M. (1996). School work culture and productivity. The Journal of experimental education, 64(2), 139-156.

Kalla, H. K. (2005). Integrated internal communications: A multidisciplinary perspective. Corporate Communication, 10, 302-314.

Kaya, Y. K. (1999). Ĕ̆itim yönetimi kuram ve Türkiye'deki uygulama (7. Baskı). Ankara: Bilim Yayıncilık.

Kaya B. (2003). Yönetsel ve iş iletişimi. Ankara: Siyasal Kitabevi.

Malmelin, N. (2007). Communication capital: modelling corporate communications as an organizational asset. Corporate communications: an international journal, 12(3), 298-310.

MEB.(2019). Resmi İstatistikler, 14.08.2019 tarihinde https://sgb.meb.gov.tr/ meb_iys-_dosyalar/2018_09/06123056_meb_istatistikleri_orgun_egitim_2017_2018.pdf adresinden erişilmiştir.

Okay, A. ve Okay, A. (2014). Halkla ilişkiler kavram strateji ve uygulamaları, İstanbul:Der Yayınları.

Smidts, A., Pruyn, A.T.H., ve van Riel, C. (2001) The impact of employee communication and perceived external prestige on organizational identification. Academy of Management Journal, 44(5), 1051-1065.

Şatır, Ç. ve Erendağ-Sümer, F. (2008). Kurum itibarının bileşenleri üzerine bir araştırma: Sağlik hizmeti üreten bir kamu kurumunda iç paydaşlar itibarı nasıl algılıyor?, Selçuk Üniversitesi İletişim Fakültesi Dergisi, 5, 1525 
Tutar, H. (2003). Örgütsel iletişim (1. Baskı ). Ankara: Seçkin Yayıncılık.

Ural, E. G. (2012). Kurumsal itibarı ölçme yöntemi olarak Türkiye itibar endeksi ve endeks sonuçlarından hareketle Türkiye' de elektronik sektörünün itibarı üzerine bir değerlendirme. AJIT-e: Online Academic Journal of Information Technology, 3, 7-20.

Welch, M. ve Jackson, P. R. (2007). Rethinking internal communication: A stakeholder approach. Corporate Communications, 12, 177-198.

Yurtsever, S. (2013). Kurumsal itibarın ölçülmesi: Karabük üniversitesinin kurumsal itibarının öğrenciler tarafından değerlendirilmesi. Yüksek Lisans Tezi, Karabük Üniversitesi Sos. Bil. Ens. İşl. Anabilim Dalı, Karabük.

\section{Kaynakça Bilgisi / Citation Information}

Çantay, N. ve Yaşar, O. (2019). Kurumsal itibar algısında örgütsel iletişimin rolü: Devlet ve özel okullarında karşılaştırmalı bir analiz. OPUS-Uluslararası Toplum Araştırmaları Dergisi, 14(20), 1161-1186. DOI: 10.26466/opus.606924 